\title{
ANTHROPOMETRIC PREDICTORS OF SYSTOLIC AND DIASTOLIC BLOOD PRESSURE CONSIDERING INTERSEXUAL DIFFERENCES IN A GROUP OF SELECTED SCHOOLCHILDREN
}

\author{
Kvetoslava Rimárová1, Erik Dorko1, Jana Diabelková1, Zlatana Sulinová1, Katarina Frank², Jana Baková3, \\ Tomáš Uhrin ${ }^{4}$, Pavol Makovický', Nikola Pelechová1, Nika Konrádyová1 \\ ${ }^{1}$ Department of Public Health and Hygiene, Faculty of Medicine, Pavol Jozef Šafárik University in Košice, Košice, Slovak Republic \\ ${ }^{2}$ Biological and Physical Sciences Department, Columbus State Community College, Columbus, Ohio, USA \\ ${ }^{31}$ st Department of Surgery, Faculty of Medicine, Pavol Jozef Šafárik University in Košice and Louis Pasteur University Hospital, Košice, \\ Slovak Republic \\ ${ }^{4}$ Department of Dermatology, Faculty Hospital of J. A. Reiman, Prešov, Slovak Republic \\ ${ }^{5}$ Department of Biology, Faculty of Education, J. Selye University, Komárno, Slovak Republic
}

\section{SUMMARY}

Objectives: Although the association between anthropometric parameters and blood pressure has been established for adults, the relationship for children has not been thoroughly studied in Slovakia. Present study investigates the association between anthropometric parameters and systolic and diastolic blood pressure in the group of randomly selected schoolchildren.

Methods: Examinations were conducted as a cross-sectional study with 760 schoolchildren from Eastern Slovakia, 381 boys and 379 girls. The blood pressure evaluation included sphygmomanometer technique (seated, 3 times repeated) measurement of systolic and diastolic blood pressure (SBP; DBP). Anthropometric measurements included: body weight, height, circumference of waist, hip and chest, BMI, WHR (waist-hip ratio), fat skinfolds measurement, triceps skinfold, and derivation of body fat percentage. The parents' questionnaires incorporated basic demographic and socioeconomic characteristics of the family, reported BMI of father and mother, and child's birth-weight and birth-length. Statistical analysis included Student's t-test gender differences in measured parameters, partial Pearson's correlations and linear regression model of the impact of body parameters Z-scores on SBP and DPB.

Results: Statistical analysis confirmed gender difference in basic anthropometric parameters. Pearson's correlations revealed highly significant relationship of anthropometric indices to SBP compared to DBP. Correlations of anthropometric parameters with SBP and DPB were more significant for boys compared to girls. Linear regression analysis showed that the highest impact on SBP and DBP had Z-score of BMI, followed by weight and height. Z-score of body weight has statistical impact on SBP and DBP in all group and group of boys $(p<0.001)$, lower significance was in DBP of girls $(p<0.01)$. Similar results were obtained for Z-score of height and BMl for SBP and DBP in both total group and group of boys on level $p<0.001$. Z-score for BMl and height in DBP has lower statistical significance.

Conclusions: Linear regression model confirmed higher statistical relationship of SBP and DBP in the group of boys compared to the group of girls. SBP correlations and linear regression model of anthropometric parameters revealed more significant outputs compared to DPB.

The results confirmed the fact that we have to consider anthropometric indices in paediatric blood pressure evaluation.

Key words: blood pressure, body height, body weight, BMI, schoolchildren

Address for correspondence: K. Rimárová, Department of Public Health and Hygiene, Faculty of Medicine, Pavol Jozef Šafárik University in Košice, Šrobárova 2, 04180 Košice, Slovak Republic. E-mail: kvetoslava.rimarova@upjs.sk

https://doi.org/10.21101/cejph.a5536

\section{INTRODUCTION}

Understanding intercultural, regional, racial and gender differences in blood pressure (BP) and anthropometric indices may help to determine the contributors of mortality from coronary artery diseases in different populations (1). Genetics, internal and external factors play a substantial role in the development of children, including body growth parameters, hypertension, obesity and other health determinants. Boys and girls develop differently in a few ways, and researchers have always been studying the external body parameters, obesity, genes, hormones, and biochemical parameters that might explain some of these differences $(2,3)$. Individual child's development may not fit neatly within gender lines. Between the big growth stages of infancy and adolescence, boys and girls grow in height and weight at about the same - slow, yet steady - rate. 
There are no significant differences between the sexes until the age of elementary school - that's when girls start to grow taller and faster, although boys catch up and exceed them within a few years. Growth parameters - body height, body weight, various circumferences, growth indexes - are clinical, research and public health tools in paediatrics to assess general health, nutritional status, well-being, risk of some diseases, hypertension $(4,5)$. The general ways in which boys and girls differ as they grow up, can help parents to prepare for early childhood and beyond (6-8).

In the case of cardiovascular disease, it takes many years to develop significant arterial changes and following functional impairment. Obesity is associated with poor cardiovascular and metabolic parameters during childhood, including high BP, abnormal lipid levels and insulin resistance. Hypertension is a global health determinant as well as an important risk factor for cardiovascular diseases, stroke, renal diseases, heart changes, and also for global mortality in adults (9-11). Until recently, hypertension was only occasionally diagnosed among children. Hypertension is currently also affecting paediatric population and childhood hypertension has become an important health issue due to its increasing prevalence also among children's population $(11,12)$.

Presently, the hypertension among children has a prevalence of $3-5 \%(13-15)$. Growing evidence about the presence of hypertension among children indicates that higher blood pressure in childhood could have unfavourable cardiovascular effects, including organ damage as well as chronic kidney disease. Risk for hypertension is mostly related with obesity in paediatric population (15).

Diagnostic criteria for hypertension or elevated blood pressure (BP) among schoolchildren might be often underdiagnosed (14). Diagnostic criteria for paediatric hypertension are mostly categorised as an average systolic and/or diastolic blood pressure that is $\geq 95$ th percentile for gender, age, and height on 3 or more separate occasions. The adult definition of prehypertension is also used for adolescents, because the 90th percentile for systolic blood pressure is $>120 \mathrm{~mm} \mathrm{Hg}$ by age of 12 years. Adolescents with blood pressure $\geq 120 / 80 \mathrm{~mm} \mathrm{Hg}$ (but $<95$ th percentile) have prehypertension $(16,17)$. Diagnostic criteria in Germany and among members of European society for hypertension are based on age, sex and body-height principles (18). The clinical guidelines recommend that hypertension or elevated blood pressure have to be confirmed with repeated (at least 3 times) measurements of BP and repeated measurements within short period of times $(16,19)$. Blood pressure measurement could be taken during paediatric controls or visits for children of 3 years and older (16).

Preventive, public health and clinical point of views are dealing with the question if there is a need to promote screening, monitoring and reporting paediatric hypertension. However, several barriers exist against systematic screening of hypertension in children (20). First obstacles could arise in the identification of border levels for elevated blood pressure, which will require treatment for children. The diagnosis of elevated blood pressure in children is based on the distribution of blood pressure in the population and these distributions can differ between the countries. Therefore it has been emphasized that precise diagnosis of hypertension requires measurements of blood pressure at repeated clinical visits, when screening issues are out of the scope. In low-resource settings, including many developing countries, universal screening of blood pressure in children would divert into limited resources (20-22).

The second barrier in screening of BP is a fact that the absolute risk of cardiovascular disease associated with a given level of blood pressure during childhood is not known. Cardiovascular diseases are rarely diagnosed before the age of 40 or 50 years, so the absolute risk is low or unnoticeable during the childhood period. Health benefit of lowering the blood pressure in children would be low, indicating low cost-effectiveness of treatment of elevated blood pressure or hypertension in children. These facts are contrasting with the solid evidence base for the adult population $(20,21,23)$.

Third obstacle is little knowledge about the long-term efficacy and safety of the antihypertensive treatment starting already in the childhood. The US Preventive Services Task Force in 2013 (24) stated that "current evidence is insufficient to assess the balance of benefits and harms of screening for primary hypertension in asymptomatic children and adolescents to prevent subsequent cardiovascular disease" $(20,21$, 23-25). The preferences in BP screening should be provided for children at high risk of hypertension. Treatment should be preferred for children with secondary hypertension $(22,23,25)$.

Standardised normative data on BP in children have long been available both in the United States and Europe. Paediatric BP standards and nomograms were developed by the Task Force on BP Control in Children (26). The percentile curves were first published in 1987 and described age-specific distributions of systolic and diastolic BPs for the age range between 5 and 17 years, with corrections for height and weight (27). Next report of the Task Force (28) was published in 1996 as an Update of the 1987 Task Force report. This report brought additional information, with regards to the diagnosis and treatment of elevated blood pressure and hypertension in infants and children. The fourth report added further information and adapted the data to growth charts previously developed by the Centres for Disease Control and Prevention in U.S.A. (16). European Society of Cardiology added a new chapter dedicated to hypertension in children, with an approach similar to the American version (29). There is a need to use specific national blood pressure standards $(30,31)$. National research results in Italy with longitudinal design based as paediatric blood pressure study confirmed that paediatric prehypertension and hypertension are equally prevalent among children in Sardinia (32).

Childhood obesity appears to detrimentally alter cardiovascular structure and function prior to the adulthood. Childhood obesity has also been associated with other near-term health effects, such as increased risk of asthma, obstructive sleep apnoea, orthopaedic difficulties, early maturation, polycystic ovarian syndrome, and hepatic steatosis.

The aim of our present study was to perform gender comparison to assess the correlations of anthropometric factors, obesity indices, body mass index (BMI), and body fat percentage, in order to identify the impact and significant relationship on systolic (SBP) and diastolic (DBP) in a selected group of schoolchildren in eastern Slovakia. 


\section{MATERIALS AND METHODS}

\section{General Information about the Survey Sample}

The research was conducted in a randomly selected samples of school children in eastern Slovakia (cities and counties of: Trebišov, Michalovce, Košice, Humenné, Vranov). Anthropometric data, skin folds measurement, blood pressure and questionnaire data were collected in outpatient paediatric primary health care during the preventive control of the child between 2014 and 2016. The study data were processed only for children whose parents signed informed written consent.

\section{Characteristics of the Sample}

Cross-sectional study included children aged 6.00 to 14.99 years. In the survey sample, 760 subjects were examined, with an overall mean age of 10.56 years, of which 381 (50.1\%) were boys and 379 (49.9\%) were girls. Chronological age of the child was calculated from the date of birth and the date of examination $(7,8,33)$.

\section{Anthropometric Data}

\section{Body weight measurement}

Body weight was measured with the medical digital scale KERN 9004 with an accuracy of $\pm 0.05 \mathrm{~kg}$. Body weight was measured in kilograms. Measurement was carried out when the child had minimum items of clothing, without shoes or heavy accessories such as coins, mobile phones, cases etc. The child was weighed in a standing position.

\section{Body height measurement}

Body height was measured by the medical digital scale KERN 9004. Body height was measured in centimetres in a direct standing position.

Body mass index (BMI)

BMI is an anthropometric index to quantify an individual's obesity level. BMI is derived from a ratio equation of body weight expressed in kilograms divided by the square of the body height in meters $\left(\mathrm{kg} / \mathrm{m}^{2}\right)$.

Body fat percentage measurement

Body fat percentage was assessed by measuring selected skin folds. Individual's height and weight are not complex indicators of an actual lean or fat mass in the human body. Thus, BMI offers very little advantage over the existing presence of the fat in the body. Skin fold measurements are used to estimate the body fat. The examination was performed with the use of calliper device HARPENDEN with calibration dowel - to measure the thickness of substantial fat stores. The assumption was that substantial fat should be proportional to overall body fat. Thus, by measuring skinfolds on several body sites, the total body fat mass may be calculated. For the measurements in our sample, we used 4 body sites and their skinfolds measurements: scapula, spina iliaca anterior superior, biceps muscle and triceps muscle. There are, however, few limitations with the skinfold measurement technique. The estimated results obtained from skinfolds measurement vary widely from technician to technician. The "art" of skin folds measurements requires the technician to properly identify a site measurement and pinch the skin to gather only the fat store and no other tissue. The error of the estimate among the technicians has been reported to be $\pm 8 \%$ (34). To prevent this bias in our sample, the measurement was done only by one skilled person who measured all skin folds, in order to prevent individual measurement bias. The percentage of fat was calculated from the sum of all four skinfolds and derived from table by Parizkova (35). We also used triceps skinfold thickness in our measurement and comparison.

Waist and Hip Circumferences, WHR (waist-hip ratio)

Waist and hip circumferences were obtained with the use of flexible and inextensible tape measure, with a resolution of $0.1 \mathrm{~cm}$, applied directly above the iliac crests. WHR (waist-hip ratio) was calculated as proportion of waist/hip circumference.

\section{Parents' Questionnaires}

The anthropometric examination was completed with a questionnaire addressed to parents or caregivers. The questionnaire included information on socio-economic characteristics of the families: parents' education, income per capita, the completeness of the family. From anamnestic records, the data about breastfeeding, birth order, births weight and length, and the incidence of chronic diseases in the family were evaluated. The questionnaire also contained basic data on reported body height and weight of the mother and father.

\section{Blood Pressure and Measurement}

Blood pressure was measured by using a mercury sphygmomanometer connected with children's cuff. The measurement was carried out at least after 30 minutes of physical activity, in a sitting position. The systolic and diastolic blood pressure values were calculated as an arithmetic mean from 3 consecutive measurements in intervals of 5-10 minutes. Hypertension in children is defined as the average SBP and/or diastolic BP (DBP) that is $\geq 95$ th percentile for gender, age, and height on 3 or more occasions. Prehypertension in children is defined as average SBP or DBP levels that are $\geq 90$ th percentile but $<95$ th percentile (16).

\section{Statistical Analysis}

For analysis of sociodemographic factors, we used simple table frequencies. Calculation of statistical intersexual difference was performed with Student's t-test for arithmetic means differences. To determine the prediction of the anthropometry parameters influencing SBP and DBP, we used the Pearson's partial correlation test with adjustment for gender and age of the child (in the case of total group - adjusted for age and gender; in the case of selected group of boys or girls - adjusted for age). For the evaluation of direct effect of body parameters (weight, height, BMI), Z-scores have been used to identify standardised impact of anthropometric parameters on SBP and DBP. Z-scores were derived from Slovak national anthropometric survey in 2001 (36). Z-scores of body parameters (body height, body weight and BMI) were included in linear regression model. Statistical analysis was performed in the IBM-SPSS version 19.

In our research study, we applied principles of the Helsinki declaration in medical research involving human subjects ca- 
pable of giving informed consent. Parent or caregiver of each potential subject was adequately informed of the aims, methods, sources of funding, any possible conflicts of interest, institutional affiliations of the researcher, the anticipated benefits and potential risks of the study and the discomfort it may entail. The parents of participated children have been informed on the right to refuse to participate in the study or to withdraw consent to participate at any time without reprisal. After ensuring that the subjects of our study have understood the information, the physician or researcher asked for a freely-given written informed consent.

\section{RESULTS}

Age categorisation table (Table 1) confirmed an equal amount of boys as well as girls in one age group. In each age group from 6.00-13.99 years -45 boys and 45 girls were randomly selected and examined. In the age group from 14.00-14.99, we examined 21 boys and 19 girls. Sample of schoolchildren consisted completely from 381 boys and 379 girls, the entire group had 760 participants.

The most common parental education level was secondary $71.9 \%$ of fathers and the same amount of mothers have graduated from secondary schools (Table 2). Demographic characteristics of the sample confirmed very high unemployment rate among mothers $(28.3 \%)$ and also in the group of fathers (23.9\%). Despite of the declining national unemployment rate, data from our study are showing a necessity to monitor rural areas of eastern Slovakia, which currently have persisting unsolved difficulties with unemployment. Single-parent families, where the child is growing up in a family of one parent (mostly mother), occurred in $38.9 \%$ of cases. Low income per capita was confirmed in $36.1 \%$ of the families. Socio-economic analysis of the sample also confirmed high smoking rate $-27.0 \%$ of mothers and $38.9 \%$ of fathers confirmed smoking more than 5 cigarettes per day (Table 2).

Intersexual gender differences in body weight, height, BMI, SBP and DBP did not show statistical gender differences (Table 3). Both the SBP and DBP were higher among boys, but not statistically significant. Anthropometric comparison confirmed

Table 1. Basic gender and age categorisation of schoolchildren group $(N=760)$

\begin{tabular}{|l|c|c|}
\hline Age (years) & $\begin{array}{c}\text { Boys } \\
\text { (n) }\end{array}$ & $\begin{array}{c}\text { Girls } \\
\text { (n) }\end{array}$ \\
\hline $6.00-6.99$ & 45 & 45 \\
\hline $7.00-7.99$ & 45 & 45 \\
\hline $8.00-8.99$ & 45 & 45 \\
\hline $9.00-9.99$ & 45 & 45 \\
\hline $10.00-10.99$ & 45 & 45 \\
\hline $11.00-11.99$ & 45 & 45 \\
\hline $12.00-12.99$ & 45 & 45 \\
\hline $13.00-13.99$ & 45 & 45 \\
\hline $14.00-14.99$ & 21 & 19 \\
\hline Total & 381 & 379 \\
\hline $\mathrm{n}-$ number of subjects & &
\end{tabular}

previously clearly well-known somatic intersexual difference in waist-hip ratio (WHR) - which was higher among boys $(p<0.001)$. Girls had significantly higher fat percentage, triceps skinfold $(\mathrm{mm})$ and hip circumference $(\mathrm{p}<0.001)$. Boys showed statistically significantly higher chest circumference $(p<0.001)$, waist circumference $(p<0.001)$, significantly higher birth weight $(\mathrm{p}<0.001)$ and birth length $(\mathrm{p}<0.001)$.

Pearson's correlation coefficients for SBP and DBP adjusted for age and gender in the total group showed statistical significance $(p<0.001)$ for body weight, height, BMI, hip, waist and chest circumference (Table 4). Lower statistical correlation was confirmed for triceps skinfold (SBP $\mathrm{p}<0.01$; DBP $\mathrm{p}<0.05$ ). BMI of mother $(p<0.01)$ and BMI of father $(p<0.05)$ had statistical correlation in total group only on SBP, but no impact on DBP.

Pearson's partial correlations adjusted for age in the group of boys confirmed highest statistical significance $(p<0.001)$ between SBP and DBP in the following parameters: body weight, BMI body height, hip, waist and hip circumferences (Table 4). Triceps skinfold did correlate $(\mathrm{p}<0.01)$ for both SBP and DBP. Lower statistical significance among boys with SBP $(p<0.05)$ was confirmed with parameter WHR, but WHR did not show statistical significance with DBP. Statistical analysis established parameters which did not have any statistical significance in the

Table 2. Demographic and socio-economic characters of the sample $(N=760)$

\begin{tabular}{|c|c|c|c|}
\hline \multicolumn{2}{|l|}{ Parameter } & $\mathrm{n}$ & $\%$ \\
\hline \multirow{2}{*}{ Gender } & Boys & 381 & 50.1 \\
\hline & Girls & 379 & 49.9 \\
\hline \multirow{3}{*}{ Mother's education } & Basic (elementary) & 99 & 13.0 \\
\hline & Secondary & 547 & 71.9 \\
\hline & University & 114 & 15.1 \\
\hline \multirow{3}{*}{ Father's education } & Basic (elementary) & 76 & 10.0 \\
\hline & Secondary & 547 & 71.9 \\
\hline & University & 137 & 18.1 \\
\hline \multirow{2}{*}{ Mother's employment } & Employed & 545 & 71.7 \\
\hline & Unemployed & 215 & 28.3 \\
\hline \multirow{2}{*}{ Father's employment } & Employed & 578 & 76.1 \\
\hline & Unemployed & 182 & 23.9 \\
\hline \multirow{2}{*}{$\begin{array}{l}\text { Completeness of the } \\
\text { family }\end{array}$} & Complete & 464 & 61.1 \\
\hline & Incomplete & 296 & 38.9 \\
\hline \multirow{2}{*}{ Income per capita } & $\operatorname{Low}(<150 €)$ & 274 & 36.1 \\
\hline & High & 486 & 63.9 \\
\hline \multirow{2}{*}{ History of hypertension } & Yes & 91 & 12.0 \\
\hline & No & 669 & 88.0 \\
\hline \multirow{2}{*}{ Birth order } & First-born & 502 & 66.1 \\
\hline & Second + next born & 258 & 33.9 \\
\hline \multirow{2}{*}{ Smoking mothers } & Yes (> 5 cig./day) & 205 & 27.0 \\
\hline & Not & 555 & 73.0 \\
\hline \multirow{2}{*}{ Smoking fathers } & Yes (> 5 cig./day) & 296 & 38.9 \\
\hline & Not & 464 & 61.1 \\
\hline
\end{tabular}


Table 3. Independent t-test of intersexual differences in anthropometric parameters in schoolchildren $(N=760)$

\begin{tabular}{|c|c|c|c|c|c|c|c|}
\hline \multicolumn{2}{|l|}{ Parameter } & $\mathrm{n}$ & $\overline{\mathbf{x}}$ & SD & $95 \% \mathrm{Cl}$ & $\mathrm{t}$-value & $\mathrm{p}$-value \\
\hline \multirow{2}{*}{ Systolic BP } & Boys & 381 & 107.38 & 10.67 & $106.30-108.45$ & \multirow{2}{*}{1.03} & \multirow{2}{*}{$\begin{array}{c}0.301 \\
\text { n.s. }\end{array}$} \\
\hline & Girls & 379 & 106.60 & 10.13 & $105.57-107.62$ & & \\
\hline \multirow{2}{*}{ Diastolic BP } & Boys & 381 & 68.40 & 8.13 & $67.58-69.22$ & \multirow{2}{*}{1.31} & \multirow{2}{*}{$\begin{array}{c}0.193 \\
\text { n.s. }\end{array}$} \\
\hline & Girls & 379 & 67.65 & 7.66 & $66.88-68.43$ & & \\
\hline \multirow{2}{*}{ Weight } & Boys & 381 & 36.94 & 12.12 & $35.72-38.16$ & \multirow{2}{*}{0.10} & \multirow{2}{*}{$\begin{array}{c}0.925 \\
\text { n.s. }\end{array}$} \\
\hline & Girls & 379 & 36.86 & 11.11 & $35.74-37.98$ & & \\
\hline \multirow{2}{*}{ Height } & Boys & 381 & 145.14 & 15.23 & $143.6-146.7$ & \multirow{2}{*}{0.25} & \multirow{2}{*}{$\begin{array}{c}0.803 \\
\text { n.s. }\end{array}$} \\
\hline & Girls & 379 & 145.41 & 14.63 & $143.9-146.9$ & & \\
\hline \multirow{2}{*}{ Body mass index } & Boys & 381 & 17.05 & 2.62 & $16.79-17.32$ & \multirow{2}{*}{0.16} & \multirow{2}{*}{$\begin{array}{c}0.873 \\
\text { n.s. }\end{array}$} \\
\hline & Girls & 379 & 17.02 & 2.53 & $16.76-17.27$ & & \\
\hline \multirow{2}{*}{ Waist-hip ratio } & Boys & 381 & 0.82 & 0.046 & $0.82-0.83$ & \multirow{2}{*}{7.99} & \multirow{2}{*}{$<\underset{* * *}{0.001}$} \\
\hline & Girls & 379 & 0.79 & 0.057 & $0.77-0.78$ & & \\
\hline \multirow{2}{*}{ Fat percentage } & Boys & 380 & 14.88 & 4.84 & $14.38-15.36$ & \multirow{2}{*}{16.88} & \multirow{2}{*}{$<\underset{* * *}{<0.001}$} \\
\hline & Girls & 373 & 20.64 & 4.56 & $20.17-21.10$ & & \\
\hline \multirow{2}{*}{ Chest circumference } & Boys & 381 & 65.8 & 8.07 & 64.99-66.61 & \multirow{2}{*}{8.41} & \multirow{2}{*}{$<\underset{* * *}{0.001}$} \\
\hline & Girls & 379 & 61.6 & 5.43 & $61.11-62.21$ & & \\
\hline \multirow{2}{*}{ Waist circumference } & Boys & 381 & 59.08 & 7.44 & $58.33-59.83$ & \multirow{2}{*}{4.53} & \multirow{2}{*}{$\underset{* * * *}{<.001}$} \\
\hline & Girls & 379 & 56.84 & 6.12 & $56.22-57.46$ & & \\
\hline \multirow{2}{*}{ Hip circumference } & Boys & 381 & 72.04 & 9.38 & $71.10-72.99$ & \multirow{2}{*}{1.89} & \multirow{2}{*}{$\begin{array}{c}0.060 \\
\text { n.s. }\end{array}$} \\
\hline & Girls & 379 & 73.34 & 9.54 & $72.37-74.30$ & & \\
\hline \multirow{2}{*}{ Birth weight } & Boys & 381 & 3468.4 & 522.5 & $3,415.8-3,520.9$ & & $<0.001$ \\
\hline & Girls & 379 & 3308.3 & 559.8 & $3,251.7-3,364.8$ & 4.08 & *** \\
\hline Rirth lenath & Boys & 381 & 50.95 & 2.55 & $50.61-51.19$ & 102 & $<0.001$ \\
\hline BIrtn lengtn & Girls & 379 & 50.21 & 2.53 & $49.91-50.42$ & 4.02 & $* * *$ \\
\hline Trisonc ckinfold & Boys & 381 & 11,57 & 7.44 & $4.22-18.55$ & 802 & $<0.001$ \\
\hline IIICEPS SKIIIUIU & Girls & 379 & 16.24 & 6.99 & $5.37-24.31$ & 0.92 & *** \\
\hline
\end{tabular}

$\mathrm{n}$ - number of subjects; $\overline{\mathrm{x}}$ - arithmetic mean; SD - standard deviation; $\mathrm{Cl}$ - confidence interval; $\mathrm{p}$-values $-{ }^{* * *}<0.001 ; \mathrm{n} . \mathrm{s}$. - not significant

group of boys on SBP and DBP - specifically, birthweight, birth length, BMI of mother and father (reported). For age-adjusted Pearson's correlation coefficients for SBP and DBP (Table 4), the group of girls manifested similar results to boys, but with lower significance. WHR did not significantly correlate with SBP and DBP. Birthweight, birth length and the BMI of both parents were not significant factors neither for SBP nor for DBP. Statistical significances with body parameters were more expressed in the group of boys compared to girls (Table 4) - for example, body weight of boys has correlation coefficient with SBP 0.363 ( $p<0.001)$ compared to impact of girls' body weight on SBP with $0.202(\mathrm{p}<0.001)$. When comparing differences in correlation coefficients between systolic and diastolic pressures, higher correlations between systolic pressure and anthropometric values can be observed.

Linear regression analysis for SBP (Table 5) showed significant associations $(p<0.001)$ between Z-scores of weight, height and BMI. The highest impact on SBP had BMI, followed by body weight and finally body height. Linear regression model confirmed higher statistical relationship of SBP in the group of boys compared to the group of girls.
Linear regression analysis for DBP (Table 6) confirmed lower significant associations between Z-scores of weight, height and $\mathrm{BMI}$ in the group of girls. Z-score of body weight has statistical impact on DBP in total group and group of boys $(p<0.001)$, lower significance was in the group of girls $(\mathrm{p}<0.01)$. Z-score manifested similar results for height and BMI - for total group and boys, relationship was calculated on level $p<0.001$; for group of girls, regression model confirmed lower significance for height $(\mathrm{p}<0.05)$ and BMI was lower as well $(\mathrm{p}<0.05)$.

\section{DISCUSSION}

Hypertension and increased levels of BP in adults are one of the major risk factors for all groups of cardiovascular diseases including acute coronary syndrome (37). In determining the blood pressure value, it is necessary to take into account the body indices, gender, body height, weight, BMI index, ethnicity, socio-demographic characteristics of the environment, genetic and other factors. One of the basic factors that modify the blood pressure in the child population is age $(5,38)$. Large 
Table 4. Pearson's correlation coefficients of anthropometric factors of children and parents with systolic and diastolic blood pressure (partial zero order correlations) $(N=760)$

\begin{tabular}{|c|c|c|c|c|c|c|}
\hline \multirow[b]{2}{*}{ Variable } & \multicolumn{3}{|c|}{ Systolic BP } & \multicolumn{3}{|c|}{ Diastolic BP } \\
\hline & $\begin{array}{c}\text { All } \\
n=760\end{array}$ & $\begin{array}{c}\text { Boys }^{B} \\
n=381\end{array}$ & $\begin{array}{c}\text { Girls }^{B} \\
n=379\end{array}$ & $\begin{array}{c}\text { All } \\
n=760\end{array}$ & $\begin{array}{c}\text { Boys }^{B} \\
n=381\end{array}$ & $\begin{array}{c}\text { Girls }^{B} \\
n=379\end{array}$ \\
\hline Weight & $\underset{* * *}{0.291}$ & $\underset{* * *}{0.363}$ & $\underset{* * *}{0.202}$ & $\underset{* * *}{0.208}$ & $\underset{* \star *}{0.261}$ & $\underset{* *}{0.145}$ \\
\hline Height & $\underset{* \star \star}{0.214}$ & $\underset{* * \star}{0.260}$ & $\underset{* *}{0.163}$ & $\underset{* * *}{0.154}$ & $\underset{* * *}{0.203}$ & $\begin{array}{c}0.100 \\
*\end{array}$ \\
\hline Body mass index & $\underset{* * *}{0.241}$ & $\underset{* * *}{0.310}$ & $\underset{* *}{0.160}$ & $\underset{* * *}{0.174}$ & $\underset{* * *}{0.226}$ & $\begin{array}{c}0.113 \\
*\end{array}$ \\
\hline Fat percentage & $\underset{* \star \star}{0.184}$ & $\begin{array}{c}0.247 \\
* * *\end{array}$ & $\begin{array}{c}0.111 \\
*\end{array}$ & $\begin{array}{c}0.117 \\
* *\end{array}$ & $\begin{array}{c}0.162 \\
* *\end{array}$ & $\begin{array}{c}0.063 \\
\text { n.s. }\end{array}$ \\
\hline Waist-hip ratio & $\begin{array}{c}0.048 \\
\text { n.s. }\end{array}$ & $\begin{array}{c}0.116 \\
*\end{array}$ & $\begin{array}{c}-0.05 \\
\text { n.s. }\end{array}$ & $\begin{array}{c}0.021 \\
\text { n.s. }\end{array}$ & $\begin{array}{c}0.026 \\
\text { n.s. }\end{array}$ & $\begin{array}{c}0.022 \\
\text { n.s. }\end{array}$ \\
\hline Waist circumference & $\underset{* * *}{0.241}$ & $\underset{* * *}{0.319}$ & $\underset{* *}{0.142}$ & $\underset{* * *}{0.167}$ & $\underset{* * *}{0.211}$ & $\begin{array}{c}0.119 \\
*\end{array}$ \\
\hline Hip circumference & $\begin{array}{c}0.243 \\
* * *\end{array}$ & 0.302 & $\underset{* *}{0.182}$ & $\begin{array}{c}0.161 \\
* * *\end{array}$ & $\underset{* * *}{0.229}$ & $\begin{array}{c}0.085 \\
\text { n.s. }\end{array}$ \\
\hline Chest circumference & $\underset{* * \star}{0.279}$ & $\underset{* \star \star}{0.339}$ & $\underset{* \star *}{0.208}$ & $\underset{* \star *}{0.188}$ & $\underset{* \star \star}{0.245}$ & $\begin{array}{c}0.134 \\
*\end{array}$ \\
\hline Birth weight & $\begin{array}{c}0.033 \\
\text { n.s. }\end{array}$ & $\begin{array}{c}0.041 \\
\text { n.s. }\end{array}$ & $\begin{array}{c}0.024 \\
\text { n.s. }\end{array}$ & $\begin{array}{c}0.044 \\
\text { n.s. }\end{array}$ & $\begin{array}{c}0.068 \\
\text { n.s. }\end{array}$ & $\begin{array}{c}0.018 \\
\text { n.s. }\end{array}$ \\
\hline Birth length & $\begin{array}{c}0.065 \\
\text { n.s. }\end{array}$ & $\begin{array}{c}0.071 \\
\text { n.s. }\end{array}$ & $\begin{array}{c}0.056 \\
\text { n.s. }\end{array}$ & $\begin{array}{c}0.065 \\
\text { n.s. }\end{array}$ & $\begin{array}{c}0.064 \\
\text { n.s. }\end{array}$ & $\begin{array}{c}0.067 \\
\text { n.s. }\end{array}$ \\
\hline Triceps skinfold & $\underset{* *}{0.186}$ & 0.251 & $\begin{array}{c}0.116 \\
*\end{array}$ & $\begin{array}{c}0.149 \\
*\end{array}$ & $\underset{* *}{0.203}$ & $\begin{array}{c}0.102 \\
*\end{array}$ \\
\hline BMI mother (reported) & $\underset{* *}{0.117}$ & $\begin{array}{c}0.086 \\
\text { n.s. }\end{array}$ & $\underset{*}{0.154}$ & $\begin{array}{c}0.068 \\
\text { n.s. }\end{array}$ & $\begin{array}{c}0.020 \\
\text { n.s. }\end{array}$ & $\underset{*}{0.124}$ \\
\hline BMI father (reported) & $\begin{array}{c}0.074 \\
*\end{array}$ & $\begin{array}{c}0.057 \\
\text { n.s. }\end{array}$ & $\begin{array}{c}0.096 \\
\text { n.s. }\end{array}$ & $\begin{array}{c}0.038 \\
\text { n.s. }\end{array}$ & $\begin{array}{c}0.020 \\
\text { n.s. }\end{array}$ & $\begin{array}{c}0.058 \\
\text { n.s. }\end{array}$ \\
\hline Birth order & $\begin{array}{c}0.055 \\
\text { n.s. }\end{array}$ & $\begin{array}{c}0.038 \\
\text { n.s. }\end{array}$ & $\begin{array}{c}0.056 \\
\text { n.s. }\end{array}$ & $\begin{array}{c}0.022 \\
\text { n.s. }\end{array}$ & $\begin{array}{c}0.031 \\
\text { n.s. }\end{array}$ & $\begin{array}{c}0.014 \\
\text { n.s. }\end{array}$ \\
\hline
\end{tabular}

$\mathrm{n}$ - number of subjects; $\mathrm{A}-$ gender and age adjusted; $\mathrm{B}$ - age adjusted; p-values $-{ }^{* * *}<0.001,{ }^{* *}<0.01,{ }^{*}<0.05 ;$ n.s. - not significant

Table 5. Linear regression of impact of Z-scores on systolic blood pressure in the group of schoolchildren $(N=760)$

\begin{tabular}{|c|c|c|c|c|c|c|}
\hline Z-score & Group & $\mathrm{n}$ & $\beta$ & $95 \% \mathrm{Cl}$ & $\mathbf{R}^{2}$ & $p$-value \\
\hline \multirow{3}{*}{ Z-score weight } & $A \| l^{\mathrm{A}}$ & 760 & 0.427 & $0.332-0.522$ & 0.381 & $<0.001^{* * *}$ \\
\hline & Boys $^{B}$ & 381 & 0.501 & $0.371-0.630$ & 0.435 & $<0.001^{* * *}$ \\
\hline & Girls ${ }^{B}$ & 379 & 0.340 & $0.200-0.480$ & 0.317 & $<0.001^{* * *}$ \\
\hline \multirow{3}{*}{ Z-score height } & $A \| l^{\mathrm{A}}$ & 760 & 0.328 & $0.223-0.432$ & 0.319 & $<0.001^{* * *}$ \\
\hline & Boys $^{B}$ & 381 & 0.403 & $0.253-0.553$ & 0.360 & $<0.001^{* * *}$ \\
\hline & Girls $^{B}$ & 379 & 0.250 & $0.104-0.397$ & 0.271 & $<0.01^{* *}$ \\
\hline \multirow{3}{*}{ Z-score BMI } & $A \| l^{\mathrm{A}}$ & 760 & 1.116 & $0.821-1.412$ & 0.347 & $<0.001^{* * *}$ \\
\hline & Boys $^{B}$ & 381 & 1.351 & $0.932-1.769$ & 0.394 & $<0.001^{* * *}$ \\
\hline & Girls ${ }^{B}$ & 379 & 0.871 & $0.451-1.290$ & 0.293 & $<0.001^{* * *}$ \\
\hline
\end{tabular}

$\mathrm{n}$ - number of subjects; $\mathrm{A}$ - gender and age adjusted; $\mathrm{B}$ - age adjusted; $\mathrm{Cl}$ - confidence interval; $\mathrm{R}^{2}$ - coefficient of determination; $\mathrm{p}$-values - ${ }^{\star *}<0.01,{ }^{\star \star *}<0.001$; Z-score - calculated from Sevcikova et al. (36)

Swedish cohort study confirmed association of cigarette smoking during pregnancy with many developmental complications, as well as with an increased offspring blood pressure in late adolescents (39).
The definition of hypertension in the paediatric population is based on the normative distribution of blood pressure in a set of healthy individuals with regards to gender, age, body growth and ethnicity of the respective population. There is no suitable 
Table 6. Linear regression of impact of Z-scores on diastolic blood pressure in the group of schoolchildren $(N=760)$

\begin{tabular}{|c|c|c|c|c|c|c|}
\hline Z-score & Group & $\mathrm{n}$ & $\beta$ & $95 \% \mathrm{Cl}$ & $\mathbf{R}^{2}$ & $p$-value \\
\hline \multirow{3}{*}{ Z-score weight } & $A\|\|^{\mathrm{A}}$ & 760 & 0.230 & $0.271-0.390$ & 0.251 & $<0.001^{* * *}$ \\
\hline & Boys $^{B}$ & 381 & 0.282 & $0.175-0.385$ & 0.282 & $<0.001^{* * *}$ \\
\hline & Girls $^{B}$ & 379 & 0.174 & $0.065-0.283$ & 0.216 & $0.002^{* *}$ \\
\hline \multirow{3}{*}{ Z-score height } & $A \| l^{\mathrm{A}}$ & 760 & 0.187 & $0.105-0.269$ & 0.210 & $<0.001^{* * *}$ \\
\hline & Boys $^{B}$ & 381 & 0.249 & $0.130-0.369$ & 0.235 & $<0.001^{* * *}$ \\
\hline & Girls $^{B}$ & 379 & 0.127 & $0.014-0.240$ & 0.184 & $0.028^{*}$ \\
\hline \multirow{3}{*}{ Z-score BMI } & $A \| l^{\mathrm{A}}$ & 760 & 0.583 & $0.349-0.817$ & 0.221 & $<0.001^{* * *}$ \\
\hline & Boys $^{B}$ & 381 & 0.756 & $0.419-1.092$ & 0.247 & $<0.001^{* * *}$ \\
\hline & Girls $^{B}$ & 379 & 0.408 & $0.083-0.734$ & 0.192 & $0.014^{*}$ \\
\hline
\end{tabular}

Z-score - calculated from Sevcikova et al. (36)

database of normative blood pressure values for children and adolescents in Slovakia (40). In practice, tables and charts of US norms from 2004 - NHBPEP (16) can be used. However, these standards are often rejected by the professional public because they contain a database of children of different ethnicities and different anthropometric characteristics from the United States of America. Children's population in Slovakia has a totally different ethnic and socio-demographic structure, it has different genetic backgrounds, other nutritional habits, and other body characteristics as children from the American continent. Research results by Regecová et al. (40) were compared to the US National Blood Pressure Education Program Working Group on High Blood Pressure in Children and Adolescents and the authors pointed to the fact that Slovak children's blood pressure is moving in the upper frontier zones of the American population and are higher than those reported in NHBPEP (2004). This confirms the need to create a database of blood pressure levels from a population of Slovak children (40).

Systematic review and meta-analysis of data from 25 studies involving 54,196 individuals found a pooled prevalence of elevated blood pressure of $5.5 \%$ and a pooled prevalence of slightly elevated blood pressure of $12.7 \%$ in children and adolescents in Africa. Increased BMI was largely associated with the prevalence of elevated blood pressure, with prevalence six times higher in obese children and adolescents than in those of normal weight (22). Our data also confirmed importance of body parameters for blood pressure evaluation. Outputs of our crosssectional study confirmed the fact that systolic blood pressure has higher statistical significance with body parameters than diastolic.

Our research results were confirmed with other literature resources (32-34) - explicitly, significant associations of blood pressure levels to body weight, body mass index, waist circumference, body fat percentage. The impact of maternal and paternal BMI on systolic and diastolic blood pressure was also confirmed in our study. The close relationship between the BMI and the blood pressure values was shown in most of the literature resources $(4,12,13,37)$. In our survey Pearson's R values were adjusted for age and gender and analysed for complete sample, boys or girls. Results demonstrated higher relationship of systolic blood pressure to anthropometric parameters compared to diastolic pressure and a closer correlation of anthropometric values in the boys group compared to girls. Using the Pearson correlation, the results of our study confirmed both BMI and height as blood pressure determinants, but the highest relationship with systolic and diastolic pressure has proven to be the weight parameters of the child, both in the group of girls and boys. Both groups - boys and girls - and both pressures (systolic and diastolic) showed the highest $\mathrm{R}$ coefficient for the $\mathrm{Z}$-score of body weight parameter $(\mathrm{R}=0.317-0.435, \mathrm{p}<0.001)$. The second most important correlation parameter for blood pressure was the children's Z-score BMI, followed by the child's height. However, the aim of our work was not to compare the blood pressure of our children with the databases, but to identify the factors that influence the most blood pressure within the investigated sample.

Limitations of the study should be noted. Our sample and design of the study is cross-sectional and includes only children form eastern Slovakia, where we confirmed inferior results of SES status (employment of parents, income per capita). Therefore, the results cannot be generalised for the whole Slovak population.

\section{CONCLUSION}

Body size parameters and anthropometric evaluation are simple and low-cost effective measurements which can contribute to hypertension evaluation in the paediatric population. Anthropometric indexes and fat percentage indicate overweight or obesity and could be connected with elevated levels of SBP and DBP. Anthropometric indices in our study correlated with blood pressure in examined schoolchildren population. The study also reports important association of Z-scores of weight, height and BMI in prediction of blood pressure. Outputs confirmed higher statistical relationship between anthropometric parameters and systolic BP compared to diastolic BP, and also the group of boys showed stronger statistical importance of anthropometric parameters and blood pressure (SBP and DBP) compared to girls. Our study provides good evidence that anthropometric indices and Z-scores in schoolchildren population could be used as a predictor of high blood pressure in this population group. The outputs also have beneficial effects on other cardiovascular diseases connected with elevated blood pressure or hypertension e.g. diabetes, dyslipidaemias, metabolic syndrome, atherosclerosis. 


\section{Acknowledgements}

This work was supported by national grant KEGA 007UPJŠ-4/2018 - principal investigator Kvetoslava Rimárová and grant UPJŠ VVGS-2018-897 - principal investigator Kvetoslava Rimárová.

\section{Conflict of Interests}

None declared

\section{REFERENCES}

1. Ma C, Liu Y, Liu X, Yin F, Lu Q. Comparison of different screening methods for hypertension in Han adolescents. Clin Pediatr (Phila). 2016;55(4):363-7.

2. Brennan L, Walkley J, Wilks R. Parent- and adolescent-reported barriers to participation in an adolescent overweight and obesity intervention. Obesity (Silver Spring). 2012;20(6):1319-24.

3. Brennan L, Walkley J, Wilks R, Fraser SF, Greenway K. Physiological and behavioural outcomes of a randomised controlled trial of a cognitive behavioural lifestyle intervention for overweight and obese adolescents. Obes Res Clin Pract. 2013;7(1):e23-41.

4. Sorof J, Daniels S. Obesity hypertension in children: a problem of epidemic proportions. Hypertension. 2002;40(4):441-7.

5. Alvarez MM, Vieira AC, Sichieri R, Veiga GV. Association between central body anthropometric measures and metabolic syndrome components in a probabilistic sample of adolescents from public schools. Arq Bras Endocrinol Metabol. 2008;52(4):649-57.

6. Tanner JM. Growth at adolescence. 2nd ed. Oxford: Blackwell Scientific; 1962.

7. Marshall WA, Tanner JM. Variations in the pattern of pubertal changes in girls. Arch Dis Childhood. 1969;44(235):291-303.

8. Marshall WA, Tanner JM. Variations in the pattern of pubertal changes in boys. Arch Dis Childhood. 1970;45(239):13-23.

9. Lackland DT, Weber MA. Global burden of cardiovascular disease and stroke: hypertension at the core. Can J Cardiol. 2015;31(5):569-71.

10. Dobson CP, Eide M, Nylund CM. Hypertension prevalence, cardiac complications, and antihypertensive medication use in children. J Pediatr. 2015;167(1):92-7, e91. doi: 10.1016/j.jpeds.2015.04.016.

11. Litwin M, Feber J, Ruzicka M. Vascular aging: lessons from pediatric hypertension. Can J Cardiol. 2016;32(5):642-9.

12. Feber J, Ahmed M. Hypertension in children: new trends and challenges. Clin Sci (Lond). 2010;119(4):151-61

13. Rosner B, Cook NR, Daniels S, Falkner B. Childhood blood pressure trends and risk factors for high blood pressure: the NHANES experience 1988-2008. Hypertension. 2013;62(2):247-544.

14. Hansen ML, Gunn PW, Kaelber DC. Underdiagnosis of hypertension in children and adolescents. JAMA. 2007;298(8):874-9.

15. Xi B, Zong X, Kelishadi R, Hong YM, Khadilkar A, Steffen LM, et al. International child blood pressure references Establishment Consortium. Establishing international blood pressure references among nonoverweight children and adolescents aged 6 to 17 years. Circulation. 2016;133(4):398-408

16. National High Blood Pressure Education Program Working Group on High Blood Pressure in Children and Adolescents. The Fourth Report on the Diagnosis, Evaluation, and Treatment of High Blood Pressure in Children and Adolescents. Pediatrics. 2004;114(2 Suppl 4th Report):555-76.

17. Falkner B, Daniels SR. Summary of the Fourth Report on the Diagnosis, Evaluation, and Treatment of High Blood Pressure in Children and Adolescents. Hypertension. 2004;44(4):387-8.

18. Neuhauser HK, Thamm M, Ellert U, Hense HW, Rosario AS. Blood pressure percentiles by age and height from nonoverweight children and adolescents in Germany. Pediatrics. 2011;127(4):e978-88. doi: 10.1542/ peds.2010-1290.

19. Kawabe H, Saito I. Which measurement of home blood pressure should be used for clinical evaluation when multiple measurements are made? J Hypertens. 2007;25(7):1369-74.

20. Chiolero A, Bovet P, Paradis G. Screening for elevated blood pressure in children and adolescents: a critical appraisal. JAMA Pediatr. 2013;167(3):266-73.
21. Chiolero A, Bovet P. Hypertension in children: from screening to primordial prevention. Lancet Public Health. 2017;2(8):e346-7. doi: 10.1016/ S2468-2667(17)30137-8.

22. Noubiap JJ, Essouma M, Bigna JJ, Jingi AM, Aminde LN, Nansseu JR. The prevalence of elevated blood pressure in children and adolescents in Africa: a systematic review and meta-analysis. Lancet Public Health. 2017;2(8):e375-6. doi: 10.1016/S2468-2667(17)30123-8.

23. Bloetzer C, Bovet P, Paccaud F, Burnier M, Chiolero A. Performance of targeted screening for the identification of hypertension in children. Blood Press. 2017;26(2):87-93.

24. Moyer VA; US Preventive Services Task Force. Screening for primary hypertension in children and adolescents: US Preventive Services Task Force recommendation statement. Ann Intern Med. 2013;159(9):613-9.

25. Hart JT. Is screening for essential hypertension in children essential? BMJ. 2008;336(7659):1452. doi: 10.1136/bmj.39619.490475.3A.

26. Blumenthal S, Epps RP, Heavenrich R, Lauer RM, Lieberman E, Mirkin B, et al. Report of the Task Force on Blood Pressure Control in Children. Pediatrics. 1977;59(5 2 suppl):I-II,797-820.

27. Report of the Second Task Force on Blood Pressure Control in Children-1987. Task Force on Blood Pressure Control in Children. National Heart, Lung, and Blood Institute, Bethesda, Maryland. Pediatrics. 1987;79:1-25.

28. Update on the 1987 Task Force Report on High Blood Pressure in Children and Adolescents: a working group report from the National High Blood Pressure Education Program. National High Blood Pressure Education Program Working Group on Hypertension Control in Children and Adolescents. Pediatrics. 1996;98(4 Pt 1):649-58.

29. Lurbe E, Cifkova R, Cruickshank JK, Dillon MJ, Ferreira I, Invitti C, et al. Management of high blood pressure in children and adolescents: recommendations of the European Society of Hypertension. J Hypertens. 2009;27(9):1719-42.

30. Bassareo PP, Marras AR, Mercuro G. About the need to use specific population references in estimating paediatric hypertension: Sardinian blood pressure standards (age 11-14 years). Ital J Pediatr. 2012;38(1):1. doi: 10.1186/1824-7288-38-1.

31. Marras AR, Bassareo PP, Mercuro G. Pediatric hypertension in Sardinia: prevalence, regional distribution, risk factors. G Ital Cardiol (Rome). 2010;11(2):142-7.

32. Marras AR, Bassareo PP, Ruscazio M. The relationship of longitudina screening of blood pressure in school-aged children in Sardinia with excessive weight. Cardiol Young. 2009;19(3):239-43.

33. Barnes HV. The Adolescent Patient. In: Walker HK, Hall WD, Hurst JW, editors. Clinical methods: the history, physical, and laboratory examinations. 3rd ed. Boston: Butterworths; 1990.

34. Stevens-Simon C, Thureen P, Barrett J, Stamm E. Skinfold calipe and ultrasound assessments of change in the distribution of subcutaneous fat during adolescent pregnancy. Int J Obes Relat Metab Disord. 2001;25(9):1340-5.

35. Parizkova J. Total body fat and skinfold thickness in children. Metabolism. 1961;10:794-807.

36. Ševčíková L, Nováková J, Hamade J, Tatara M, Janechová H, et al. Body development of children and youth in Slovak Republic. Results of VI. National survey in 2001. Public Health Authority of Slovak Republic: Bratislava; 2004. (In Slovak.)

37. Alberty R, Studenčan M, Kováŕ F. Prevalence of conventional cardiovascular risk factors in patients with acute coronary syndromes in Slovakia Cent Eur J Public Health. 2017;25(1):77-84.

38. Moser DC, Giuliano ICB, Titski ACK, Gaya AR, Coelho-e-Silva MJ, Leite N. Anthropometric measures and blood pressure in school children. J Pediatr. 2013;89(3):243-9.

39. Högberg L, Cnattingius S, Lundholm C, D‘Onofrio BM, Långström N, Iliadou AN. Effects of maternal smoking during pregnancy on offspring blood pressure in late adolescence. J Hypertens. 2012;30(4):693-9.

40. Regecová V, et al. Distribution of blood pressure values of children and adolescents in Slovakia - multicentre study. Kardiológia. 2007; 16 Suppl 1:26. (In Slovak.)

Received August 13, 2018 Accepted in revised form December 27, 2018 